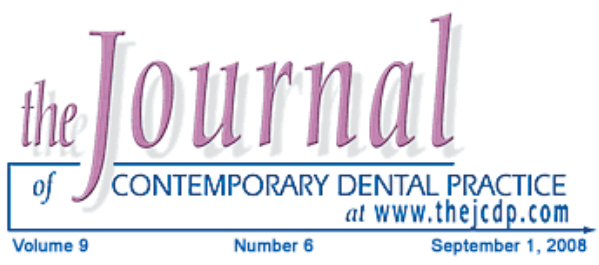

\title{
Panoramic Radiographic Appearance of Massive Calcification of Tuberculous Lymph Nodes
}

\author{
M. Isa Kara, DDS; Defne Yeler, DDS, PhD; \\ Hasan Yeler, DDS, PhD; Sinan Ay, DDS, PhD
}

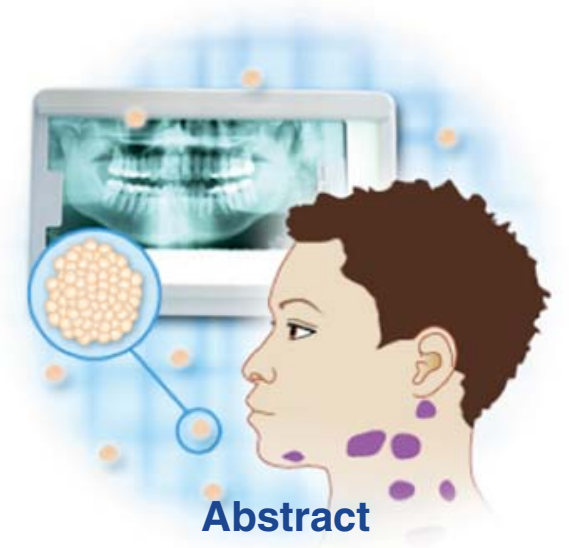

Aim: The aim of this report is to present a case of multiple calcified tuberculous lymph nodes found in a panoramic radiograph including a discussion of the differential diagnosis of this lesion from other soft tissue calcifications.

Background: Concomitant massive submandibular and cervical tuberculosis lymph node calcifications are relatively uncommon lesions and may be encountered on routine panoramic radiographs.

Report: This report describes the case of an asymptomatic 35-year-old patient whose dental radiographs showed findings which led to bilaterally, irregularly shaped, multiple calcified lymph nodes especially in the left submandibular and cervical area.

Summary: Because treatment is unnecessary for symptom-free calcified lymph nodes and the patient was unwilling to any further examination done, surgical removal of the calcified lymph nodes was not done.

Keywords: Tuberculosis, lymph node, calcification, panoramic radiography

Citation: Kara IM, Yeler D, Yeler H, Ay S. Panoramic Radiographic Appearance of Massive Calcification of Tuberculous Lymph Nodes. J Contemp Dent Pract 2008 September; (9)6:108-114.

(c) Seer Publishing 


\section{Introduction}

Tuberculosis is an infectious granulomatous disease, most commonly caused by Mycobacterium tuberculosis, which remains a public health problem worldwide. ${ }^{1}$ The incidence of tuberculosis, although decreasing in the developed countries, recently shows a resurgence with the global pandemic of AIDS, immigration, and drug resistance. $^{2}$

Tuberculosis is classified as both pulmonary and extrapulmonary. Tuberculosis of the lymph nodes is one of the most frequent forms of extrapulmonary tuberculosis. After successful treatment, tuberculosis calcification in the lymph node can reoccur but prevalence is generally low. Calcified lymph nodes are usually asymptomatic, and no treatment is indicated even if the etiology is unknown. ${ }^{3,4}$

\section{Case Report}

A 35-year-old man applied to our faculty clinic for extraction of his impacted third molar tooth. Panoramic radiographic examination revealed an impacted third molar tooth in the right mandible without pathological formation. Of interest were several massive, irregularly shaped, radiopaque lesions observed bilaterally on the radiograph. The left side of the radiograph showed large, multiple, symptomless, radiopaque masses in the submandibular region, below the angle, and adjacent to the vertebrae and mandibular angle. There were only small radiopaque masses observed in the right side of the radiograph (Figure 1).

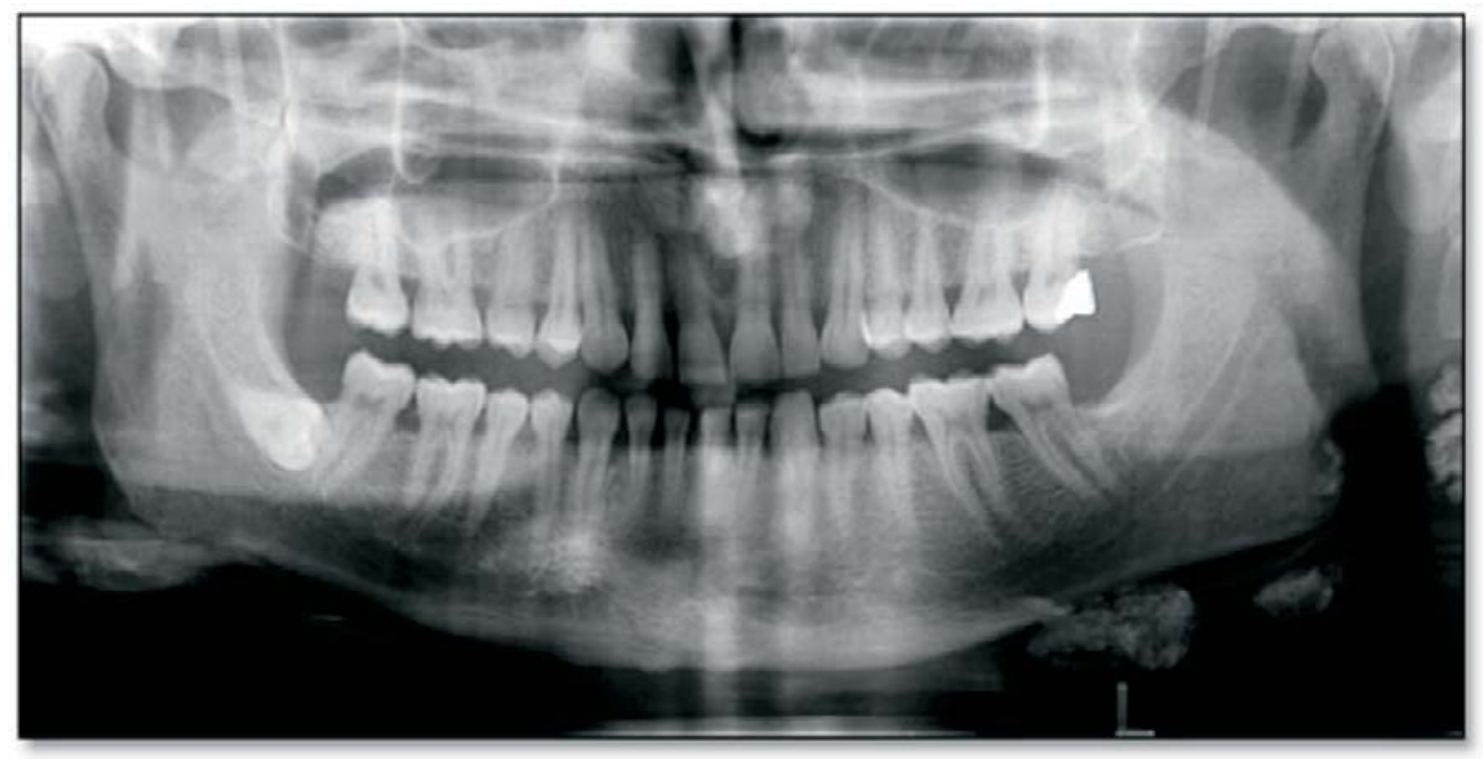

Figure 1. Several calcified lymph nodes are seen in the panoramic radiograph. 
An extraoral examination was done which revealed scar formation on the left submandibular area.

Palpation revealed hard, non-movable, non-tender nodules in the submandibular and cervical tissues.

A detailed medical anamnesis was taken which exposed a significant history of extrapulmonary tuberculosis while the other findings in the medical history were non-contributory. The complete blood count, biochemistry tests, and the renal function tests were all within normal limits, especially the levels of calcium and phosphate which excluded any possibility of disorders of bone and mineral metabolism.

The patient had suffered from this disease when he was about 13-14 years old. The patient reported a history of severe inflammation in the tonsils at that time and about two weeks later a discharging sinus tract formed involving the two lymph nodes, simultaneously.
The patient's tuberculin test was positive, and there was no abnormality found in the plain chest radiographic film. Computerized tomography (CT) revealed multiple calcified lymph nodes in the left submandibular and cervical areas. The largest node was $2.5 \mathrm{~cm}$ in diameter. Calcified lymph nodes were also noted at the level of the right submandibular gland (Figure 2). Although, there was no abnormal appearance in the nasopharynx, oropharynx, parotid and pharyngeal region, a retention cyst was observed in the left maxillary sinus.

Patient was unwilling to undergo further examination due to the absence of any symptoms. Based on his past history and some diagnostic tests a diagnosis of tuberculous lymph node calcification was made.

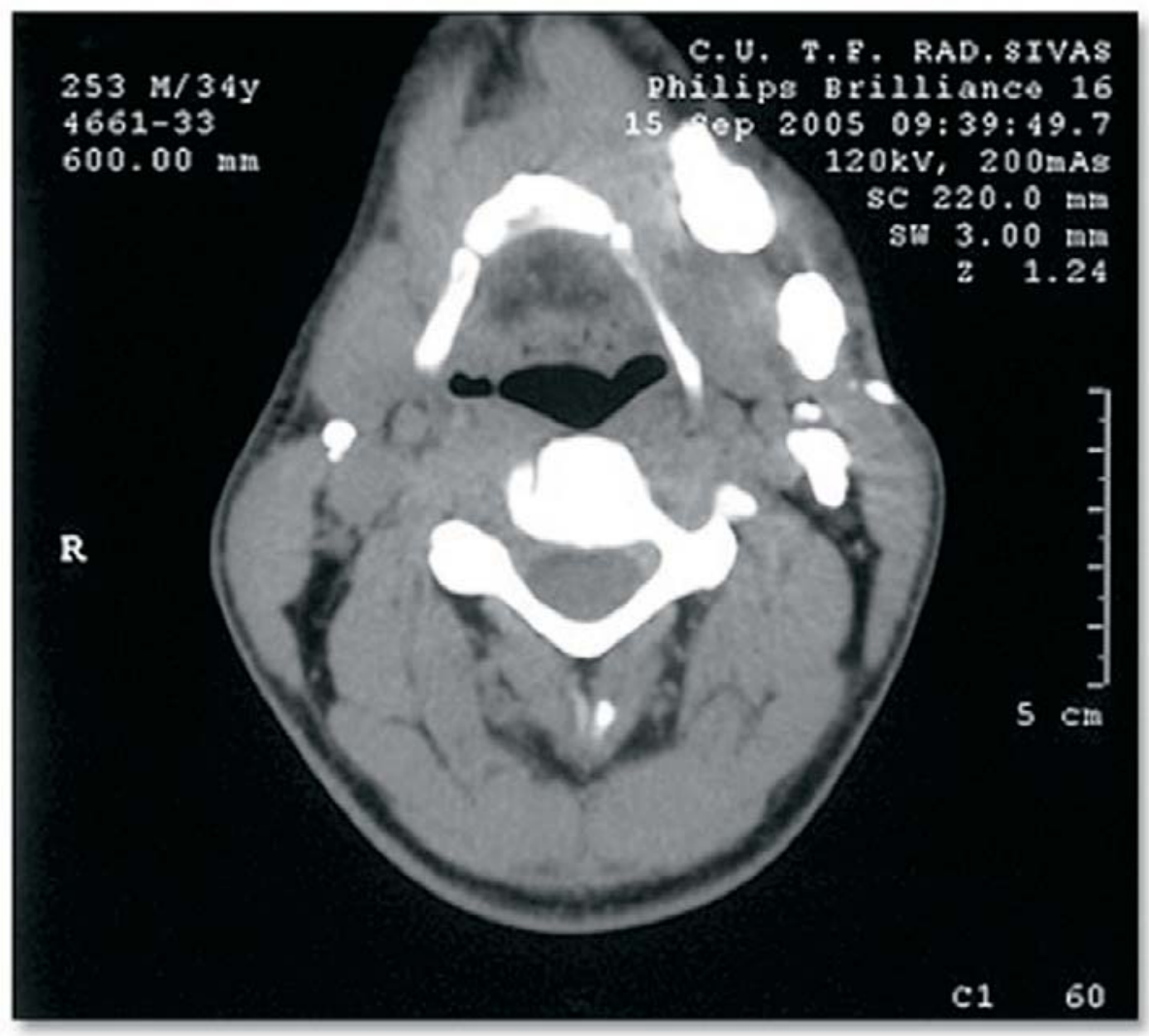

Figure 2. Several calcified lymph nodes are seen in the CT image. 


\section{Discussion}

Tuberculosis is an infectious granulamatous disease which has recently re-emerged as an important worldwide public health problem, mostly caused by Mycobacterium tuberculosis. ${ }^{1,5}$ Eight million people are infected with tuberculosis each year, three million of whom die of the disease. AIDS, leukemia, diabetes, or problems like a depressed immune system and low socioeconomic conditions such as war, poverty, overcrowding, and migration all influence the rise of tuberculosis. ${ }^{2}$

This disease appears most frequently in males, ${ }^{6}$ and this disparity has been attributed to various factors such as cigarette smoking, genetic or hormonal factors, iron status, alcohol consumption, delay in diagnosis, or associated diseases. ${ }^{7}$ The portal of entry is often the mouth, usually the tonsils or nasopharynx, and the infection is probably of bovine origin from ingested untreated milk. ${ }^{8}$

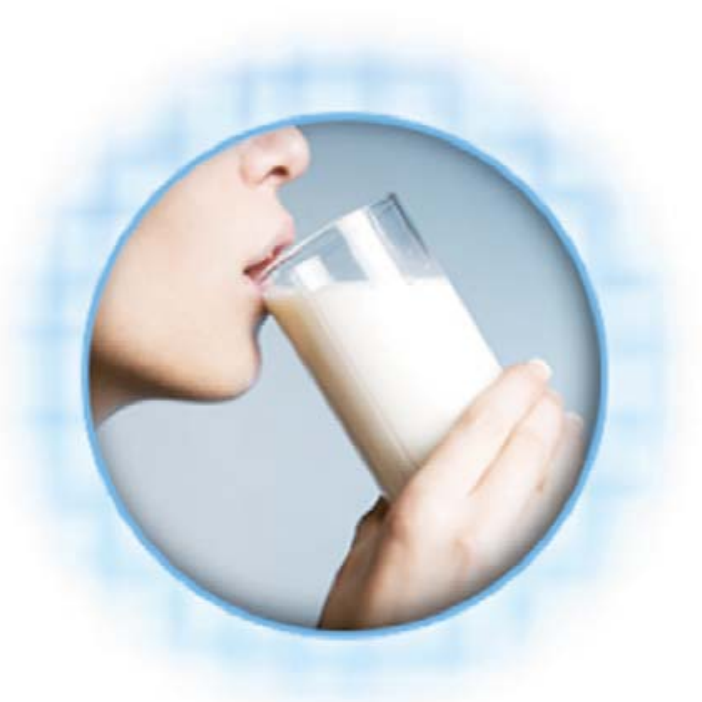

Tuberculosis is classified as both pulmonary and extrapulmonary. Extrapulmonary tuberculosis is defined as tuberculosis lesions producing disease outside the lungs and it can affect virtually any organ system. ${ }^{9,10}$ The organ systems frequently affected by extrapulmonary tuberculosis are lymph nodes, pleura, genitourinary system, central nervous system, bones and joints, gastrointestinal system, pericardium, and peritoneum. ${ }^{9}$ Although the majority of cases of tuberculosis occur among males, extrapulmonary tuberculosis most frequently appears among females. ${ }^{7}$ In the present case the lymph nodes were affected, which corroborates the literature although the patient was a male. It has been reported previously these patients usually have constitutional symptoms (fever, night sweats, and weight loss) and local features related to the site of disease. ${ }^{11}$ Although calcified lymph nodes were generally characterized by a scarcity of symptoms, scars and swelling may be found in the neck area. ${ }^{4,8}$

Tuberculosis lymphadenitis (scrofula) is common in Southern Asia. Developed countries have been less concerned about tuberculosis lymphadenitis because of its low incidence. However, this trend is beginning to reverse despite the availability of effective chemotherapy as a result of the correlation of some conditions, especially between increased prevalence of HIV infection and the development of multi drug-resistant strains of Mycobacterium tuberculosis. ${ }^{7,9}$ Unfortunately, it still remains a major health problem in Turkey where the incidence of tuberculosis in 2000 was reported as $27 / 100,0000^{2,12}$

Fine needle aspiration is the most frequent and useful diagnostic technique available to diagnose lymph node tuberculosis. ${ }^{13}$ The role of the contrast CT scan is also very important for an etiologic diagnosis of lymphadenopathy. Central hypodensity and a peripherally contrast enhanced appearance is typically observed in lymph node tuberculosis on a CT scan. ${ }^{12}$

Principally the treatment of extrapulmonary tuberculosis is medical, and the results of administration on effective chemotherapy are very satisfactory. ${ }^{14}$ Despite the fact prevalence is usually low, the occurrence of calcium phosphate deposits in the nodes may be seen after treatment of tuberculosis. ${ }^{15,16}$ Nodal calcification associated with infection is usually dystrophic in nature and related to necrosis. ${ }^{15}$

Calcified lymph nodes are a type of dystrophic calcification that occurs in lymph nodes in the healing process following various diseases. ${ }^{4,15}$ Pybus $^{8}$ stated, if the primary focus was removed or cured at an early stage, the lymph nodes would frequently subside and undergo fibrosis, a natural cure could result, and small hard lymph nodes would often disappear. In spite 
of the fact caseation can occur, it is followed by calcification when the disease became transiently quiescent, and it could again become active some years later. ${ }^{8}$

Tuberculosis calcification most frequently occurs in the chest and abdomen's node, and neck node calcification related to tuberculosis is much less common than calcification in nodes elsewhere in the body with an incidence of only $1-7 \% .{ }^{17}$ As reported here, the widespread calcification in the submandibular and cervical lymph nodes are uncommon.

The differential diagnosis of lymph node calcification includes histoplasmosis, tuberculosis, Bacille Calmette-Guérin (BCG) vaccination, coccidiomyosis, filariasis, and lymphoma, as well as metastases from a distant osteosarcoma and other calcifying neoplasms. Of all these examples, calcification following tuberculosis is a relatively common finding. ${ }^{3}$

On panoramic radiographs, there are many kind of soft tissue calcifications that mimic lymph node calcifications including a sialolith or salivary stone, stylohyoid ligament calcification, calcified blood vessels, miliary osteoma of the skin (osteoma cutis), myositis ossificans, tonsilolith, dystrophic calcification of the oropharynx, acne scars, and cysticercosis. ${ }^{18}$ Lymph node calcification must also be differentiated from other radiopaque images including foreign bodies, ghost images, and lesions of the bone, such as odontoma, sclerosing osteitis, Garre's osteomyelitis, fibrous dysplasia, idiopathic osteosclerosis, and osteoma. ${ }^{9,19,20}$ Identification of the position of the calcification in relation to the mandible is difficult using traditional radiographic techniques. ${ }^{19}$

The calcified lymph node may be single or multiple, unilateral or bilateral, lying in a roughly linear orientation, and the periphery may be well defined and usually irregular, sometimes having a lobulated appearance resembling a cauliflower. ${ }^{4}$ In the present case calcified lymph nodes appearance on radiographs can be described as bilateral, multiple, irregularly shaped, radiopaque masses. One of the most frequent soft tissue calcifications found in this area is the sialolith or salivary stone especially related with submandibular and parotid gland..$^{18}$ In the hilar region, differentiation between these two lesions might be difficult. Generally, the border of sialolith is smooth whereas calcified lymph node is commonly irregular or lobulated and patients with sialolith have symptoms related to the salivary gland. In order to diagnose precisely sialography can be performed. ${ }^{4}$

\section{Summary}

Because treatment is unnecessary for symptomfree calcified lymph nodes and the patient in the present case was unwilling to any further examination done, surgical removal of the calcified lymph nodes was not done. 


\section{References}

1. Ito FA, de Andrade CR, Vargas PA, Jorge J, Lopes MA. Primary tuberculosis of the oral cavity. Oral Dis 2005; 11(1):50-3.

2. Ilgazli A, Boyaci H, Basyigit I, Yildiz F. Extrapulmonary tuberculosis: clinical and epidemiologic spectrum of 636 cases. Arch Med Res 2004; 35(5):435-41.

3. Muto T, Michiya H, Kanazawa M, Sato K. Pathological calcification of the cervico-facial region. $\mathrm{Br} \mathrm{J}$ Oral Maxillofac Surg 1991; 29(2):120-2.

4. White SC, Pharoah MJ. Oral radiology principles and Interpretation. 4th ed. St. Louis: Mosby, 2000.

5. Ishikawa K, Hoshinaga K, Maruyama T, Izumitani M, Shiroki R. Mycobacterium tuberculosis infection of bilateral cervical lymph nodes after renal transplantation. Int J Urol 2001; 8(11):640-2.

6. Long NH, Johansson E, Diwan VK, Winkvist A. Different tuberculosis in men and women: beliefs from focus groups in Vietnam. Soc Sci Med 1999; 49(6):815-22.

7. Cailhol J, Decludt B, Che D. Sociodemographic factors that contribute to the development of extrapulmonary tuberculosis were identified. J Clin Epidemiol 2005; 58(10):1066-71.

8. Wright SM. Massive calcification following tuberculosis. Oral Surg Oral Med Oral Pathol 1988; 65(2):262-4.

9. Aydin U. Tuberculous lymph node calcification detected on routine panoramic radiography: a case report. Dentomaxillofac Radiol 2003; 32(4):252-4.

10. Swart JG, de Flamingh DQ, Hamersma T. Histologically detected extrapulmonary tuberculosis in the head and neck region. A review of 222 cases. S Afr Med J 1987; 71(11):700-2.

11. Harries AD. Tuberculosis in Africa: clinical presentation and management. Pharmacol Ther 1997; 73(1):1-50.

12. Öztop A, Ünsal I, Özgü A, Özgüven S, Köse I, Çakmak R. 1999-2002 Yılları Arasında Kahramanlar Verem SavaSı Dispanseri'ne Yapılan Tüberkülozlu Hasta Bildirimlerinin Degerlendirilmesi. Toraks Dergisi 2005; 6(3):243-50.

13. Chao SS, Loh KS, Tan KK, Chong SM. Tuberculous and nontuberculous cervical lymphadenitis: a clinical review. Otolaryngol Head Neck Surg 2002; 126(2):176-9.

14. Cooper DG, Fazal MA, Willıams RL. Isolated tuberculous osteomyelitis of the bones of the hindfoot: a case report and review of the literature. Foot and Ankle Surgery 2001; 7(3):181-5.

15. Sakae $T$, Yamamoto $\mathrm{H}$. Crystals and calcification patterns in two lymph node calcifications. J Oral Pathol 1987; 16(9):456-62.

16. Ahuja A, Ying M. Grey-scale sonography in assessment of cervical lymphadenopathy: review of sonographic appearances and features that may help a beginner. $\mathrm{Br} \mathrm{J}$ Oral Maxillofac Surg 2000; 38(5):451-9.

17. Gormly K, Glastonbury CM. Calcified nodal metastasis from squamous cell carcinoma of the head and neck. Australas Radiol 2004; 48(2):240-2.

18. Katz JO, Langlais RP, Underhill TE, Kimura K. Localization of paraoral soft tissue calcifications: the known object rule. Oral Surg Oral Med Oral Pathol 1989; 67(4):459-63.

19. Monsour PA, Mendoza AR. Panoramic ghost images as an aid in the localization of soft tissue calcifications. Oral Surg Oral Med Oral Pathol 1990; 69(6):748-56.

20. Sezer B, Tugsel Z, Bilgen C. An unusual tonsillolith. Oral Surg Oral Med Oral Pathol Oral Radiol Endod 2003; 95(4):471-3. 

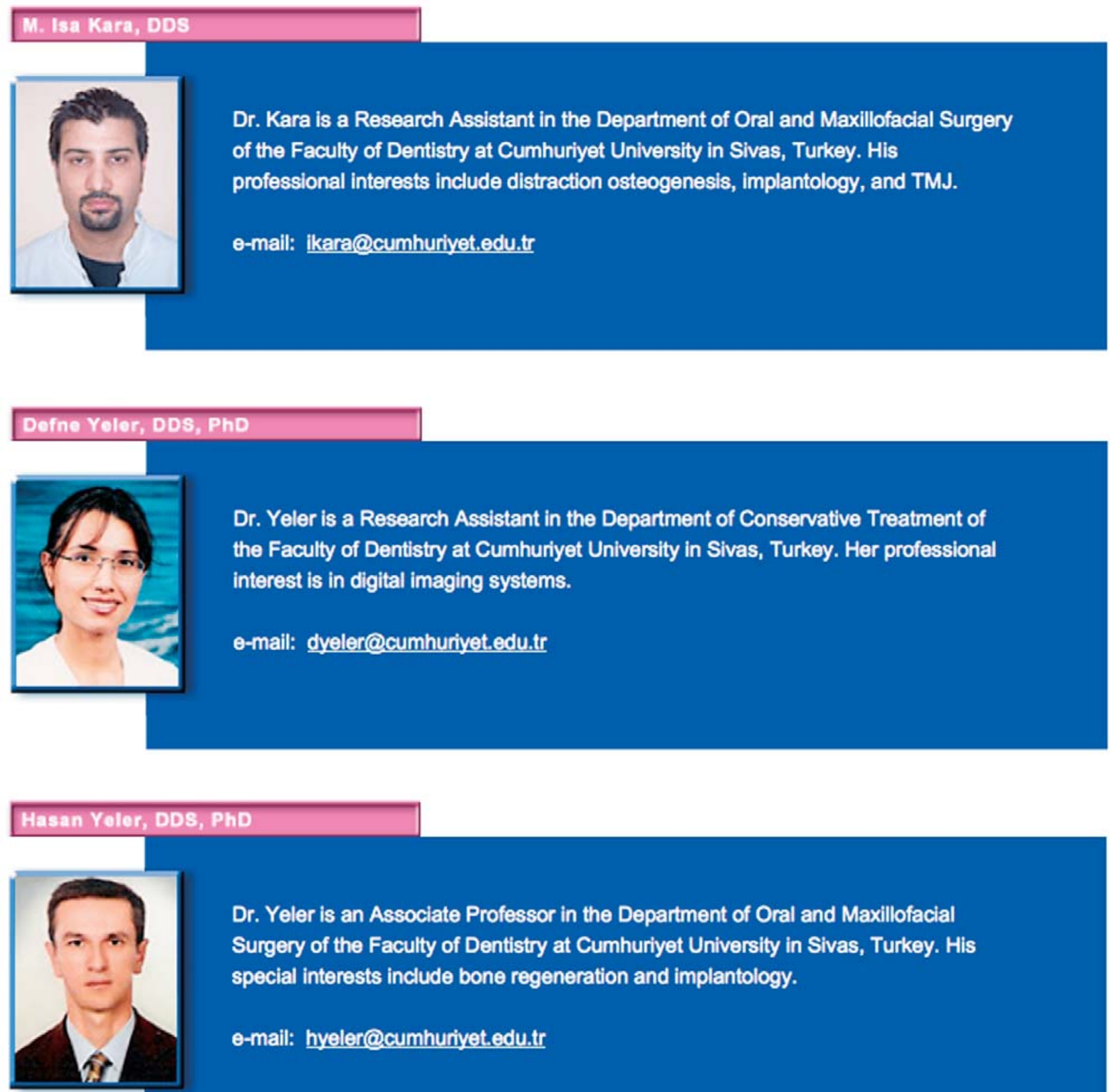

Dr. Yeler is an Associate Professor in the Department of Oral and Maxillofacial Surgery of the Faculty of Dentistry at Cumhuriyet University in Sivas, Turkey. His special interests include bone regeneration and implantology.

o-mail: hyeler@cumhuriyet.edu.tr 


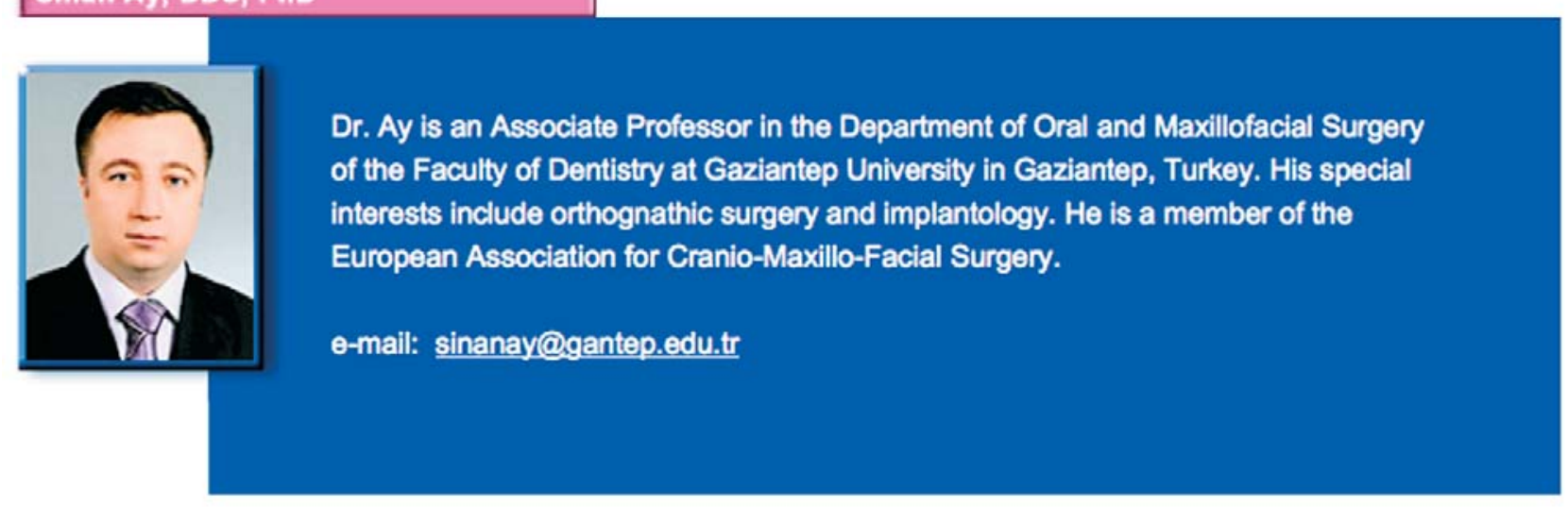

